\title{
MILITARIZACÃO DAS ESCOLAS DA REDE ESTADUAL DE GOIÁS: A NOVA ONDA CONSERVADORA
}

\author{
MILITARIZATION OF THE SCHOOLS OF THE STATE NETWORK OF GOIÁS: THE \\ NEW CONSERVATIVE WAVE
}
MILITARIZACIÓN DE LAS ESCUELAS DE LA RED ESTADUAL DE GOIÁS: LA NUEVA OLA CONSERVADORA

\author{
Paula Cristina Pereira Guimarães* \\ rural.paula@gmail.com \\ Rodrigo de Azevedo Cruz Lamos** \\ rodrigo1281@yahoo.com.br
}

\begin{abstract}
REVISTA PEDAGÓGICA
Revista do Programa de Pós-graduação em Educação da Unochapecó | ISSN 1984-1566

Universidade Comunitária da Região de Chapecó | Chapecó-SC, Brasil Como referenciar este artigo: GUIMARÃES, P. C. P.; LAMOS R. A. C. Militarização das escolas da rede estadual de Goiás: a nova onda conservadora. Revista Pedagógica, Chapecó, v. 20, n. 43, p. 66-80, jan./abr. DOI: http://dx.doi.org/10.22196/rp.v20i43.4004
\end{abstract}

\begin{abstract}
RESUMO: Este trabalho apresenta o andamento da pesquisa sobre o recente e aligeirado processo de militarização de parte das escolas da rede estadual de ensino do Estado de Goiás. O artigo resulta de uma pesquisa acerca deste processo, que transfere para a Polícia Militar de Goiás uma parte das escolas do ensino básico, através de uma parceria entre as Secretarias Estaduais de Educação e de Segurança Pública. Uma mistura de privatização com militarização. O objetivo da pesquisa é analisar a emergência de novos modelos de gestão das escolas de educação básica, a partir da inserção das polícias militares nas escolas públicas e seus desdobramentos. Trata-se de uma pesquisa básica, de análise de caráter explicativo, que se insere na categoria de pesquisa de tipo levantamento. Para a coleta de dados, foi utilizada revisão de literatura de análise de fontes bibliográficas primárias e secundárias, leis e decretos e os documentos que regem o funcionamento das escolas militarizadas.
\end{abstract}

Palavras-chave: Reforma Gerencial do Estado. Novos Modelos de Gestão Escolar. Polícia Militar de Goiás. Escola Pública.

ABSTRACT: This article presents the progress of the research on the recent and lightened process of militarization of part of the schools of the State of Goiás State. The article a research about this process, which transfers to the Military Police of Goiás a part of the schools of the State of Goiás. basic education, through a partnership between the State Secretariats of Education and Public Security. A mixture of privatization and militarization. The objective of the research is to analyze the emergence of new models of management of basic education schools, from the insertion of the military police in public schools and their unfolding. It is a basic research, of analysis of explanatory character, that falls into the category of research of type survey. For data collection, literature review was used to analyze primary and secondary bibliographic sources, laws and decrees and the documents that govern the operation of militarized schools.

Keywords: State Management Reform. New School Management Models. Goiás Military Police. Public School.

RESUMEN: Este trabajo presenta el progreso de la investigación sobre el reciente y aligerado proceso de militarización de parte de las escuelas de la red estatal de enseñanza del Estado de Goiás. El artículo una investigación sobre este proceso, que transfiere a la Policía Militar de Goiás una parte de las escuelas del Estado, a través de una asociación entre las Secretarías Estaduales de Educación y de Seguridad Pública. Una mezcla de privatización con militarización. El objetivo de la investigación es analizar la emergencia de nuevos modelos de gestión de las escuelas de educación básica, a partir de la inserción de las policías militares en las escuelas públicas y sus desdoblamientos. Se trata de una investigación básica, de análisis de carácter explicativo, que se inserta en la categoría de investigación de tipo levantamiento. Para la recolección de datos, se utilizó revisión de literatura de análisis de fuentes bibliográficas primarias y secundarias, leyes y decretos y los documentos que rigen el funcionamiento de las escuelas militarizadas.

Palabras clave: Reforma Gerencial del Estado. Nuevos Modelos de Gestión Escolar. Policía Militar de Goiás. Escuela Pública. 
* Graduada em Pedagogia pela Universidade Federal Rural do Rio de Janeiro (UFRRJ). Funcionária Pública no Rio de Janeiro. Discente no Programa de Pós-Graduação em Educação pela UFRRJ.

** Professor Adjunto do Departamento Educação e Sociedade (DES) e do Programa de Pós-Graduação em Educação, Contextos Contemporâneos e Demandas Populares (PPGEduc) na Universidade Federal Rural do Rio de Janeiro (UFRRJ). Doutor em Educação pelo Programa de Pós-graduação em Educação (PPGE) da Universidade Federal do Rio de Janeiro (UFRJ) com apoio da Coordenação de Aperfeiçoamento de Pessoal do Ensino Superior (CAPES). Mestre em Educação pelo PPGE-UFRJ (2010). Bacharel e licenciado em História pela Universidade Federal Fluminense (UFF/2005).

\section{INTRODUÇÃO}

A pesquisa que resultou neste artigo propõe uma investigação sobre a recente inserção das instituições de segurança do Estado brasileiro na gestão das administrações públicas de ensino nos sistemas estaduais de educação. O movimento de entradas da polícias militares nas redes públicas de ensino vem ocorrendo no país em diferentes estados. E este processo tem assumido formas distintas dependendo do estado da federação, e as polícias estaduais protagonizam papéis diversos no interior das escolas públicas. O Estado de Goiás vem implementando, nos últimos anos, uma das mais importantes reformas no campo educacional de que se tem notícia, uma vez que a Policia Militar assume a gestão e administração de um crescente número de escolas públicas do Estado.

A escola pública no Brasil se expandiu enormemente entre as décadas de 1970 e 2000, destacadamente a partir da década de 1990. Entretanto, esse crescimento não foi acompanhado pelo aumento dos valores do financiamento da educação pública. Em todo este período, o financiamento da educação pública brasileira nunca ultrapassou os $3 \%$ do Produto Interno Bruto (PIB). Esse crescimento das escolas brasileiras, tanto em termos do número de matrículas, quanto em suas responsabilidades, sem um respectivo aumento do financiamento, produziu como efeito uma espécie de "ampliação para menos" da escola brasileira.

Segundo Algebaile (2009, p. 46), a função da escola foi ressignificada com o processo de reformas iniciado a partir da década de 1990 e da implantação da Lei de Diretrizes e Bases (LDB) - Lei ${ }^{\circ}$ 9394, de 20 de dezembro de 1996. Nessa perspectiva, somente por meio da educação seria possível reduzir as desigualdades sociais e combater a pobreza, utilizando como justificativa a Teoria do Capital Humano. A partir dessa conjuntura, a ampliação das ofertas de vagas na educação básica, com o objetivo de diminuir os índices de evasão escolar e analfabetismo, se caracterizou em políticas educacionais marcadas pelo assistencialismo onde foram incorporados no cotidiano escolar um conjunto de responsabilidades e funcionalidades que não são típicos da escola como o desenvolvimento de hábitos primários de alimentação, higiene pessoal e etc.

Nesse contexto, diversos autores têm identificado a relação entre este processo de "ampliação para menos" das escolas públicas e a intensificação da precariedade do trabalho escolar. Essa precariedade é formada por diversos fatores, incluindo a violência escolar, tema no campo educacional de diversas pesquisas. $\mathrm{O}$ fenômeno da violência no cenário escolar não é algo novo, e muito menos pontual, países como Estados Unidos, Portugal e o Brasil ratificam que esse é um problema mundial. Nesse sentido, diversos trabalhos tentam traçar um diagnóstico, expor soluções possíveis através de projetos de cunho social desenvolvidos tanto por educadores como pela sociedade civil, porque 
não se trata somente de um assunto restrito ao ambiente escolar. A violência adentrou aos muros da escola em um movimento de fora para dentro e se tornou um desafio de todas esferas, sejam elas políticas, sociais e econômicas. Então, por causa da sua complexidade, esse assunto não deve ser analisado isoladamente.

\section{A CRISE ESTRUTURAL DO CAPITAL E A RECOMPOSIÇÃO BURGUESA}

$\mathrm{Na}$ atual conjuntura, torna-se imprescindível para a compreensão das reformas dos Estados nacionais e da administração pública considerar o contexto socioeconômico formado a partir da "crise estrutural do capital" (MÉSZAROS, 2009, p. 24) e o consequente movimento de recomposição burguesa que impulsionou a reorganização da mediação dos conflitos de classe. A crise é estrutural na medida em que se torna possível identificar um desequilíbrio sistêmico em diversas dimensões da vida social e que não se limita somente ao setor econômico. Nesse sentido, podemos identificar diversas crises, que, quando somadas segundo a conceituação de István Mészaros, assumem "a forma de uma crise endêmica, cumulativa, crônica e permanente" (MÉSZAROS, 2009, p. 18).

Essas diversas crises que afetam o espectro vital da vida humana e social que, em escala global, se desdobra em uma crise ambiental, energética, ideológica, política, moral, cultural, econômica, etc.; assim, marca o fim dos ciclos que o capital vinha passando desde então. Esses ciclos eram marcados por períodos de expancsão e crise, ou seja, momentos de acumulação e perda. Isso ocorreu até o final dos anos de 1960 e início dos anos de 1970. Ricardo Antunes (2009) explica, na introdução do livro $A$ crise estrutural do capital, como István Mészaros identifica essa nova fase do capital:

Mészaros indicava que o sistema de capital (e, em particular do capitalismo), depois de vivenciar a era dos ciclos, adentrava em uma nova fase, inédita, de crise estrutural, marcada por um continuum depressivo que faria aquela fase cíclica anterior virar história. Embora pudesse haver alternância em seu epicentro, a crise se mostra longeva e duradoura. (ANTUNES, 2009 apud MÉSZAROS, 2009, p. 10).

A crise estrutural do capital foi definida por Mészaros (2009) como o processo de ruptura nos marcos do sistema capitalista com o modelo de reprodução denominado como fordismo, a partir da década de 1970, quando as taxas de lucratividade decresceram por longos anos e pôs fim ao "ciclo de ouro do capitalismo" (HOBSBAWN, 1995, p. 253). Desde então, a burguesia, classe dominante no sistema capitalista, vem em um movimento de recomposição 
do modelo de acumulação perdido. É nesse contexto que surgiram os novos modelos de gestão do trabalho para substituir o modelo pautado no fordismo/keynesianismo.

Dessa forma, o conceito Gramsciniano de bloco histórico nos ajuda a compreender a dimensão da crise estrutural do capital na medida em que expõe a falência do bloco histórico formado desde os anos 1930-1970 que é modelo fordista/keynesianista e suas relações sociais de produção. Esse bloco representa a totalidade de um dado momento histórico. Essa totalidade é formada por duas instâncias. A primeira instância é a da infraestrutura/estrutura, ou seja, as relações de produção do bloco histórico, no caso o fordismo, que é o modelo de organização das relações de produção. Já a segunda parte Gramsci chama de instância "superestrutural" do bloco, e esta possui duas dimensões: sociedade política somada à "sociedade civil". Para Gramsci, o bloco histórico é formado pela junção da estrutura e a superestrutura dessa junção resulta o conceito de Estado Ampliado. A esse respeito o autor discorre sobre estruturas e superestruturas:

A estrutura e as superestruturas formam o "bloco histórico", isto é, o conjunto complexo e contraditório das superestruturas é o reflexo das relações sociais de produção. Disto discorre: só um sistema totalitário de ideologias reflete racionalmente a contradição da estrutura e representa a existência das condições objetivas para a subversão da práxis. (GRAMSCI, 2011, p. 187-188).

Para Gramsci, as duas dimensões não estão dissociadas; ao contrário, as duas se desenvolvem e se inter-relacionam em um movimento dinâmico, contínuo e recíproco. Gramsci diz que nos estados tipo oriental essa superestrutura possui uma única dimensão que é dimensão da sociedade política, é formada pelos entes do Estado, por exemplo, a polícia, o exército, o poder judiciário, os ministérios, etc., já a "sociedade civil" é formada por organizações sociais, sindicatos, igreja, alinhadas aos interesses hegemônicos (burgueses) e está inserida no modelo de Estado de Bem-Estar Social mais conhecido como Welfare State. Quando nos referimos à dimensão da infraestrutura, não estamos nos referindo a algo relativo à parte de física de um prédio ou de uma fábrica, e sim no espectro das relações sociais de produção que atravessam todo bloco histórico aqui estudado (Figura 1). 


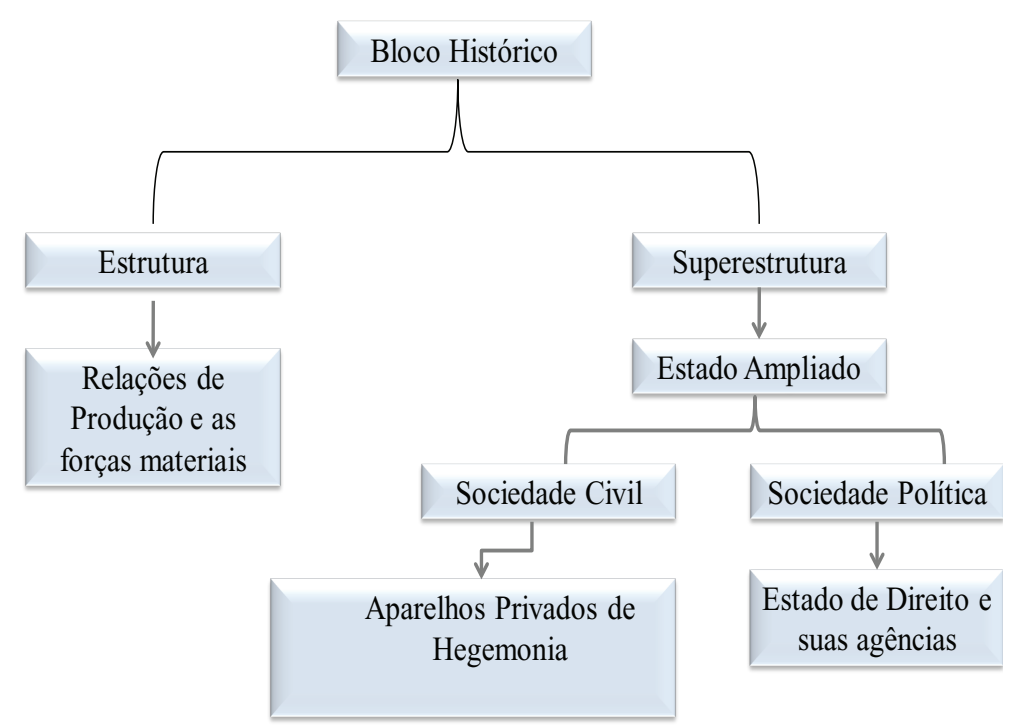

Figura 1 - Quadro Conceitual do Bloco Histórico em Gramsci Fonte: ?

Nessa conjuntura, há a crise estrutural do bloco histórico que foi erigido pelo fordismo pós-Primeira Guerra Mundial, teve seu início em meados de 1920 e se estendeu até meados da década de 1970. Gramsci, a partir de uma perspectiva mais ampla, associou o novo modelo de produção fordista ao modo de vida americano e suas concepções, denominando-o de americanismo. Este processo aprimorou novas formas de aumentar a produtividade do trabalho fabril, no mesmo espaço de tempo, além de moldar a classe de trabalhadora, a partir da difusão do novo modo de vida americano. A partir do referencial teórico-metodológico gramsciniano, Tiradentes (2012, p. 47) analisou a questão da seguinte forma:

Constituem, para Gramsci, a expressão de um modelo que combina ao mesmo tempo persuasão e coerção. Persuasão, por fortalecer os vínculos do empregado com relação à empresa; coerção, por traduzir-se, em última instância, em mecanismo de racionalização extrema, entendida como extensão, até a exaustão, da capacidade produtiva individual.

Gramsci (2011) defende que esse estreitamento das relações sociais produtivas entre indústria e trabalhador foi essencial para a manutenção e para o fortalecimento do ideário hegemônico da "sociedade fordista".

\section{FUNDAMENTOS HISTÓRICOS DA EMERGÊNCIA DE NOVOS MODELOS DE GESTÃ̃ DA ADMINISTRAÇÃO PÚBLICA NO BRASIL}

É necessário, inicialmente, explicitar os fundamentos políticos e ideológicos que determinaram o modo como 
a Reforma Neoliberal foi sendo construída no estado brasileiro, a partir da década de 1990, e que resultou em uma série de outras reformas tendo como uma das mais significativas a Reforma da Educação. A Reforma educacional do Estado brasileiro nada mais foi do que o cumprimento de uma agenda internacional recomendada por países desenvolvidos, de uma série de exigências. Os países em desenvolvimento teriam, então, de executar uma reestruturação política e econômica para se alinharem ao capital globalizado. Como o Estado se tornou pesado e ineficiente, essa ideia foi amplamente difundida e serviu como prerrogativa para a implementação das reformas.

Inúmeros organismos multilaterais, intelectuais e educadores publicaram artigos e documentos que serviram de base para a implantação das políticas públicas voltadas para a educação, a exemplo do Banco Mundial, BIRD, BID, UNESCO, FMI, UNICEF, PNUD, Cepal e etc.

A Unesco, por meio do Relatório Jacques Delors, faz um levantamento do contexto da globalização no final século XX, capaz de apontar alguns fenômenos sociais causados pela globalização em escala planetária, por exemplo, desemprego e exclusão social, mesmo em países desenvolvidos. Por meio deste relatório, foi possível compreender a revisão política educacional em vários países e enfatizando a papel da educação na erradicação de tais fenômenos sociais.

Nessa conjuntura, o Brasil iniciou, em 1995, A Reforma Gerencial do Estado brasileiro através do Ministério de Administração Federal e Reforma do Estado (MARE); e, entre 1995 a 1998, o papel do Estado foi reformulado a priori na esfera federal. A frente do MARE, Luiz Carlos Bresser-Pereira, então Ministro da Fazenda, nos primeiros quatro anos do governo FHC formulou as propostas da Reforma Gerencial do Estado de 1995. As propostas apresentadas por Bresser-Pereira foram pautadas na administração por resultados, ou seja, trouxe a metodologia de funcionamento das empresas privadas para a burocracia estatal, com a justificativa de tornar o Estado mais eficiente no que tange à prestação de serviços de monopólio do Estado - como saúde, educação e segurança -, com a desculpa de que o Estado não conseguia ofertar serviços de qualidade.

Com o Plano Diretor da Reforma do Estado brasileiro (1995), foram traçadas estratégias para delimitar a abrangência da ação estatal, distinguindo aquelas atividades que eram realmente responsabilidade do Estado e transferindo para outras esferas da sociedade, competências, a princípio com atividades sociais e culturais, que deveriam ser delegadas a organizações "públicas não estatais" que receberiam a denominação de Organizações Sociais. Quanto à atuação do Estado (BRESSER-PEREIRA,1998).

[...] (a) as delimitações das funções do Estado reduzindo seu tamanho em termos principalmente de pessoal através de 
programas de privatização, terceirização e publicização (este último processo implicando a transferência para o setor público não-estatal [sic] dos serviços sociais e científicos que hoje o estado presta) [...]. (BRESSER-PEREIRA, 1998, p. 61).

A proposta apresentada por Bresser-Pereira foi pautada na administração por resultados, ou seja, trouxe a metodologia de funcionamento das empresas privadas para a burocracia estatal, com a justificativa de tornar o Estado mais eficiente no que tange à prestação de serviços de monopólio do Estado - por exemplo: saúde, educação e segurança -, com a desculpa de que o Estado não conseguia ofertar serviços de qualidade.

A reforma educacional do estado brasileiro materializada sob a forma de políticas públicas se configurou em uma ressignificação do papel do Estado, agora propagador de uma cultura cidadã, por meio da qual a sociedade civil pode interagir nos assuntos estatais mediante uma democracia participativa. Segundo Macedo e Lamosa (2015, p. 135):

[...] A ideia de democracia participativa direta significa a implementação de novas formas de representação social na qual os cidadãos devem estar dispostos a pressionarem e contribuírem para as transformações necessárias, que do nosso ponto de vista levam aos ajustes exigidos pela nova "sociedade do conhecimento".

Essa ideia de participação social está intrinsecamente ligada ao novo modelo gerencialismo estatal. Nesse contexto, o Estado amplia sua capacidade de regulação na medida em que transfere para a sociedade civil parte de sua responsabilidade e oferece um papel político maior.

A partir da conjuntura de ampliação da oferta de vagas na educação básica com o objetivo de diminuir os índices de evasão escolar e analfabetismo, as políticas educacionais passaram a estar fortemente marcadas pelo assistencialismo, incorporadas no cotidiano escolar por meio de um conjunto de responsabilidades e funcionalidades que não são típicos da escola como o desenvolvimento de hábitos primários de alimentação, higiene pessoal etc. (ALGEBAILE, 2009, p. 20) enfatiza que essa ampliação não foi construída em uma visão de uma educação de qualidade, mas como um fator minimizador das tensões sociais com o objetivo de atenuar a pobreza. Nesse contexto, o próprio conceito de qualidade passou a ser ressignificado. E foi neste contexto que frações da classe dominante, organizadas no movimento Todos Pela Educação, passaram a anunciar o "apagão educacional” no país.

A tese do "apagão educacional" foi utilizada, segundo Santos (2012, p. 7), como justificativa para o sequestro da escola pública. A tese de que a escola pública projetada 
na transição do regime ditatorial para a democracia havia fracassado, tornou-se a principal justificativa para a emergência de novos modelos de gestão do trabalho escolar inseridos nos sistemas estaduais e municipais de ensino. De acordo com entusiastas dos novos modelos de gestão do trabalho escolar, estes deveriam proporcionar a diminuição da violência, indisciplina, evasão e a repetência. É neste contexto que se verifica a difusão do novo modelo de gestão militarizada das escolas públicas, presente em diferentes sistemas estaduais de ensino no país, e que teve no sistema público de ensino do estado de Goiás sua experiência mais avançada.

\section{O NOVO MODELO DE GESTÃO MILITARIZADA DA ESCOLA PÚBLICA NO ESTADO DE GOIÁS}

Com o pressuposto de diminuir a violência e melhorar o desempenho dos alunos em uma ambiente seguro tanto para os alunos quanto para professores e funcionários, o governo de Goiás, a partir de uma parceria entre as Secretarias Estaduais de Segurança Pública e de Educação, firmou convênio para que escolas públicas sejam repassadas à Polícia Militar. Cabe destacar que as escolas selecionadas estão localizadas em sua maioria na periferia, onde há altos índices de homicídios e com baixos índices de aproveitamento no Exame Nacional do Ensino Médio (ENEM). É nessa conjuntura que a presente pesquisa se debruça, no sentido de investigar esse novo modelo de gestão implementado pelo governo do estado em sua política de terceirização da educação, abordando os aspectos econômicos e sociais que atingem diretamente os jovens da periferia em situação de vulnerabilidade social.

Em 2001, foi criado o CPMG (Colégio da Polícia Militar de Goiás) - antigo Colégio Estadual Hugo de Carvalho Ramos - com a Lei Estadual no 14.050 (GOIÁS, 2001a), através da Lei de iniciativa do Executivo, aprovada pela Assembleia Legislativa em caráter de urgência, transformou escolas estaduais em instituições de ensino geridas pela Polícia Militar do Estado de Goiás (PMGO). Entre os motivos apresentados oficialmente, estão a violência escolar e o baixo rendimento escolar dos alunos, compreendendo que o segundo problema está diretamente relacionado ao primeiro. Nesse sentido, a solução apresentada entusiasticamente tem sido o Modelo Militarizado de Gestão Escolar.

É importante ressaltar que, nos últimos anos, esse processo tem se intensificado; e até 2007 foram criados no Estado seis colégios, o Polivalente Modelo Vasco dos Reis e o Hugo de Carvalho Ramos; dois na cidade de Anápolis, o Ayrton Senna e os CPMG de Anápolis; o CPMG de Rio Verde; e o CPMG de Itumbiara (GOIÁS, 2007). A partir de 2013, o Estado de Goiás acelerou o processo de transferência das escolas públicas para a PM. A Assembleia Legislativa aprovou a Lei Estadual $n^{\circ} 18.342$ (GOIÁS, 
1 Consultar: <https://feego.fe.ufg. $\mathrm{br} / \mathrm{n} / 82211-3$-nota-publica-do-forum-estadual-de-educacao-de-goias $>$.
2013) e criou mais seis colégios. Em julho do ano seguinte, foi aprovada a Lei $\mathrm{n}^{\circ} 18.556$, de 25 de junho de 2014, alcançando a marca de 27 colégios. Com a Lei $\mathrm{n}^{\circ} 18.967,22$ de julho de 2015, foram transformadas mais 12 escolas no mês de julho de 2015. A Lei ${ }^{\circ} 19.122$, de 27 de novembro de 2015, mudou a administração de mais duas e, em maio de 2016, de mais duas; e, de acordo com Goiás (2001a), em julho de 2016, chegou ao número de 47 CPMG no Estado, através da Lei $\mathrm{n}^{\circ}$ 19.066, de 30 de setembro de 2015. E o governo continua as transferências com mais cinco escolas. A repercussão foi grande devido ao aumento do número de escolas que foram militarizadas, o que acabou chamando a atenção da mídia nacional, havendo inúmeras reportagens sobre as escolas que colocaram a questão da violência como pano de fundo e mostrando a melhoria significativa do desempenho dos alunos dessas escolas nos exames nacionais, demonstrando claramente que os aparelhos privados de hegemonia estão altamente comprometidos com o projeto político hegemônico do Estado, na difusão e na criação de um consenso.

Esse novo Modelo Militarizado de Gestão Escolar vêm se apresentando como a solução para a problemática da violência escolar; por isso, vêm seduzindo parte da sociedade civil as propostas oficiais de melhoria substancial do rendimento de seus alunos, visto que a notável diminuição do número de reprovações e a introdução da disciplina militar com princípios norteados pela hierarquia e disciplina chamam a atenção de uma parte da sociedade, que anseia por uma educação de qualidade e que seus filhos estejam seguros na escola. É importante destacar que a emergência dos novos Modelos Militarizados de Gestão Escolar tem encontrado resistências. Em nota publicada pelo Fórum Estadual de Educação de Goiás (FEE-GO), manifesta-se uma posição contrária ao projeto de Lei que regulamenta a militarização de parte das escolas, ressaltando que é competência do governo de Goiás garantir uma escola pública de qualidade e não transferir essa competência para a Polícia Militar, cuja missão constitucional difere enormemente do projeto de educação do MEC ${ }^{1}$.

Nesse sentido, é necessário diferenciar os CPMG dos CM (Colégios Militares) - colégios "tradicionais", principalmente no que tange à formação, pois estes últimos direcionam a formação de seus alunos para o preenchimento das fileiras das instituições militares em todo o território brasileiro (oficiais e praças), já que são gestados pelas forças militares que compõem a esfera federal (Marinha, Exército e Aeronáutica); o que diverge contundentemente dos colégios que foram militarizados, que, apesar de possuírem algumas similaridades, pelo fato de a estrutura ser militarizada/hierarquizada, não possuem como finalidade a formação dos alunos para as carreiras militares, muito menos para serem policiais.

Apesar de, em seu discurso, o Governo de Goiás apre- 
sentar intenções de promover a formação pautada na gestão democrática das escolas, a contradição se dá na forma de estruturar o sistema que rege essas escolas. De acordo com o Regimento Interno dos Colégios da Polícia Militar, foi possível montar um organograma para uma melhor compreensão. E este nos permite avaliar de maneira clara o conflito entre o discurso governamental e a estrutura hierarquizada comuns das instituições militares (Figura 2).

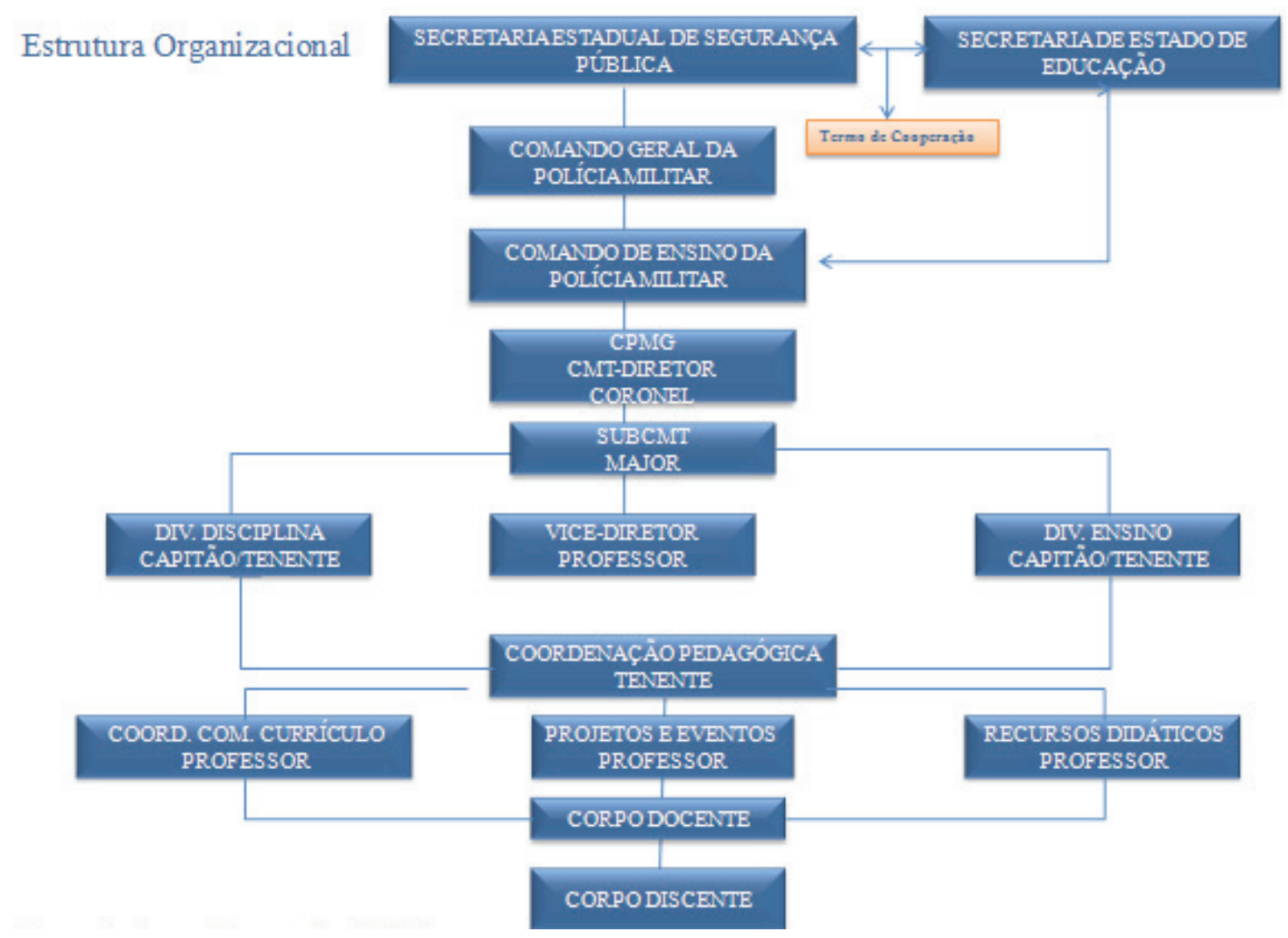

Figura 2

Fonte: Regulamento Interno dos CPMG's

Ao observarmos a distribuição dos cargos e das responsabilidades dentro da esfera estatal, constatamos que existe uma distribuição hierárquica a ser seguida. E, de acordo o Regimento Interno, os cargos de chefia estão concentrados dentro da esfera da Polícia Militar, cuja função é designar os funcionários civis cedidos pela Secretaria de Estado de Educação (SEDUCE) através do Termo de Cooperação. Com base na hierarquia militar dos CPMGs, demonstrada no organograma apresentado, podemos perceber que, no chamado "Estado Maior" dos CPMGs, nenhum cargo é ocupado por professores, cabendo a estes o papel secundário na promoção da educação nas escolas da Polícia Militar. Os oficiais que ocupam os cargos diretivos dos CPMG são, em sua maioria, oficiais da reserva com 
2 Disponível em: <https://www.opopular. com.br/editorias/cidade/goi\%C3\%A1ster\% $3 \%$ A1-mais-dez-col\% 3 3 A9gios-dapol\% 3 \%ADcia-militar-em-2018-saibaonde-1.1241190>.

3 Ver: <http://www1.folha.uol.com.br/ educacao/2015/08>. formação na área de educação e que têm interesse em participar do processo seletivo.

O Comando de Ensino da Polícia Militar é o órgão responsável pela seleção dos policiais militares que irão trabalhar nas escolas, tanto praças quanto oficiais. $\mathrm{O}$ atual comandante de Ensino da Polícia Militar é o Coronel Anésio Barbosa Júnior. E, em entrevista ${ }^{2}$ veiculada em março de 2017, este enfatizou o sucesso do novo modelo educacional com a divulgação do ranking do Exame Nacional do Ensino Médio (Enem) de 2016 em Goiás, no qual os colégios sob a gestão da PMGO ocuparam os cinco primeiros lugares da rede.

Em 2015, o quantitativo total de escolas militarizadas distribuídas pelas cinco regiões do país eram de 79 (Gráfico 1) ${ }^{3}$. Contudo, dados atuais fornecidos pelo Comando de Ensino Seção de Ensino Civil da Polícia Militar de Goiás é de que existem 54 Unidades do CPMG criadas em Lei, e 36 destas estão em funcionamento enquanto outras 18 aguardam implantação.

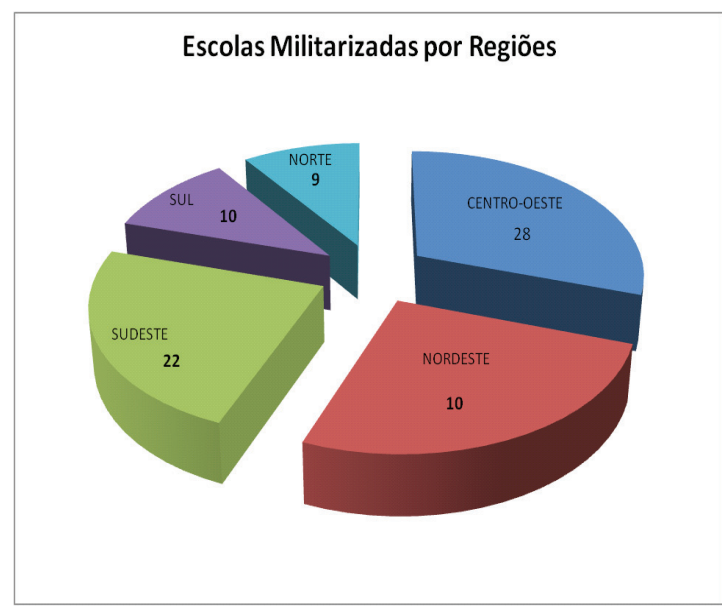

Gráfico 1

Fonte:?

A questão paradoxal ao projeto de militarização é a cobrança de taxa realizada por essas escolas e que se tornou alvo de inúmeras críticas por parte da comunidade escolar, de professores e da associação de pais e alunos. Por serem instituições custeadas com o dinheiro público, essa cobrança se torna indevida. Os prédios das escolas já estão construídos, e a manutenção deles é feita pelo Estado, que também paga o salário dos professores. E essa taxa fere, também, os dispositivos legais da Lei ${ }^{0}$ 9.394/96 que versa sobre o "ensino público" e "gratuito" como uma das responsabilidades do Estado. Contudo, a Polícia Militar denomina essa cobrança de "contribuição voluntária", não obrigatória e que é destinada para prover as despesas gerais a fim de melhorar a qualidade do serviço do CPMG. De acordo com o Regimento Interno que versa sobre a contribuição: 
Art. 147. São contribuições voluntárias doadas pelos pais ou responsáveis pelos alunos: § $1^{\mathrm{o}}$ Contribuição esporádica, mediante solicitação e destinação prévia, com material de uso geral ou pedagógico destinada a prover a seção de Recursos Didáticos e Serviços Gerais. $\S 2^{\circ}$ Contribuição voluntária feita por cada pai ou responsável pelos alunos, durante $o$ ano letivo, destinada a prover as despesas gerais do CPMG para a melhoria do ensino. (2015, p. 47).

Outra diferença seria o modelo de ingresso de novos alunos nas escolas e a reserva de 50\% das vagas a serem destinadas aos filhos de policiais militares e os outros 50\% destinados ao sorteio público aberto à comunidade estudantil, mediante inscrição para a participação do processo seletivo. Assim, sendo o governo entra em contradição novamente, na medida a reserva de vagas obriga os alunos que não foram sorteados a procurarem outra escola, fato que contraria o que determinam o Estatuto da Criança e do Adolescente (ECA) e a LDB, que tratam sobre o direito que o aluno tem de se matricular em uma escola próxima a sua casa, um direito que estará ameaçado.

Verifica-se, portanto, que o novo modelo de gestão militarizada das escolas públicas, apesar de exibir melhorias nos índices de evasão, distorção idade-série e nas avaliações externas, não foi concebido para ser universalizado. Neste sentido, mantém-se com uma rede de escolas, no interior de uma rede mais ampla, com uma gestão diferenciada que não se propõe a ser ampliada para todas as escolas brasileiras. Assim, as bases conservadoras, às quais estão submetidos os discentes matriculados nas escolas geridas sob este modelo, podem servir como um farol para reformas cada vez mais reacionárias na educação brasileira.

\section{CONCLUSÃo}

$\mathrm{O}$ artigo conclui que esse movimento de transferência das escolas públicas no estado de Goiás tem seduzido grande parte da sociedade civil, devido à melhoria substancial no desempenho dos exames nacionais, a diminuição dos casos de violência dentro e fora da escola e que são defendidas pelo governo estadual como exemplo de sucesso. Somado a isso, a mídia exerce uma importante influência no processo de criação de um consenso, como mecanismo de difusão desse novo modelo gestão. Existe um movimento dos canais midiáticos que corroboram para a aceitação social do projeto neoliberal na medida em que formam cidadãos adestrados e conformados para o trabalho simples somado a uma consciência acrítica que servirá a uma ordem voltada para os interesses da classe dominante detentora dos meios de produção com o agravante de sequer perceberem isso. 
Na medida em que o espaço público materializado na escola pública passa a ser estruturado de forma militarizada, sob a égide da disciplina e hierarquia, o novo modelo gestão militar aprofunda ainda mais o dualismo histórico pelo qual a educação brasileira vem sendo constituída, servindo aos interesses do capital por intermédio de uma elite burguesa e que evidencia, de forma latente, dois tipos de formação: uma voltada para formação dos filhos da classe trabalhadora e outra para os da elite. A primeira funciona como uma política de conformação das massas, e a Polícia Militar é deslocada do seu eixo funcional para o qual ela foi criada, para servir como instrumento de controle utilizado pelo Estado na medida em que submete os discentes a padrões de comportamento. Assim, a relação de poder imposta hierarquicamente também contribui para a omissão de violências por meio de uma política de docilização dos corpos e controle social.

Tendo como abordagem metodológica o materialismo histórico, o excurso deste trabalho é, portanto, parte constitutiva que possui em seu cerne uma profunda reflexão sobre esse movimento conservador que vem adentrando na escola pública e se materializando sob a forma de políticas públicas, ressignificando o papel do Estado, que transfere para outra esfera a responsabilidade da educação básica.

Nesse sentido, podemos perceber que a parte mais afetada são os estudantes, os pais e os profissionais da educação. Uma educação de qualidade não se faz apenas com infraestrutura adequada e com estudantes aprovados em testes e vestibulares. Devemos pensar para além das aprovações nos exames nacionais. Para isso, será preciso uma reflexão sobre o que se pretende com esse tipo de formação, para quê e para quem se pretende formar. A formação, como a entendemos, não se limita aos processos de disciplina, treinamento e condicionamento.

\section{REFERÊNCIAS}

Algebaile, Eveline. Escola Pública e Pobreza no Brasil: A Ampliação para menos. Rio de Janeiro: Lamparina, Faperj, 2009.

\section{ANTUNES (2009).}

BRESSER-PEREIRA, Luís Carlos. Os primeiros passos da reforma gerencial do Estado de 1995. Revista Brasileira do Direito Público - RDB, Belo Horizonte, ano 6, n. 23, p. 145-186, 1998.

COMANDO DE ENSINO DA POLÍCIA MILITAR - GO. Regimento Interno do Colégio da Polícia Militar de Goiás. Disponível em: <http \\cpmganapolis.net/wpcontent/uploads/2015/05/regimento_interno.pdf > Acesso em: 15 jan. 2017. 
CMB. Histórico do Colégio Militar de Brasília. <http://www.cmb.ensino.eb.br/index.php/informacoes-uteis-sobre-o-cmb/historico-docolegio-militar-de-brasilia>. Acesso em: 15 jan. 2017.

FÓRUM DE EDUCAÇÃO DE GOIÁS. $3^{\mathbf{a}}$ Nota Pública do Fórum Estadual de Educação de Goiás. 30 jul. 2015. Disponível em: <https://feego.fe.ufg.br/n/82211-3-nota-publica-do-forum-estadual-de-educacao-de-goias $>$ Acesso em: 15 jan. 2017.

GOIÁS. Lei no 14.044, de 21 de dezembro de 2001. Dispõe sobre as unidades do Colégio da Polícia Militar do Estado de Goiás (CPMG). Diário Oficial do Estado, Cidade?, 26 de dezembro de 2001a.

. Lei $\mathrm{n}^{0}$ 14.050, de 21 de dezembro de 2001. Dispõe sobre a criação, instalação e transferência de Unidades na Polícia Militar do Estado de Goiás e dá outras providências. Diário Oficial do Estado, Cidade?, 26 de dezembro 2001b.

. Lei $\mathrm{n}^{0} 16.152$, de 26 de outubro de 2007. Promove a fusão das Unidades Escolares da Secretaria da Educação e da Polícia Militar que especifica. Diário Oficial do Estado, Cidade?, 12 de novembro de 2007.

Lei $\mathrm{n}^{0}$ 18.342, de 30 de dezembro de 2013. Dispõe sobre a criação, na Polícia Militar do Estado de Goiás, da unidade que especifica e dá outras providências. Diário Oficial do Estado, Cidade?, 31 de dezembro de 2013.

Lei $\mathrm{n}^{0}$ 18.556, de 25 de junho de 2014. Dispõe sobre a criação do Colégio da Polícia Militar de Goiás CPMG - que menciona e dá outras providências. Diário Oficial do Estado, Cidade?, 26 de junho de 2014.

Lei ${ }^{0}$ 18.967, de 22 de julho de 2015. Dispõe sobre a transformação das unidades de ensino que especifica em Colégios Militares e dá outras providências. Diário Oficial do Estado, Cidade?, 24 de julho de 2015.

GOVERNO DO ESTADO DE GOIÁS. Gabinete da Casa Civil. Lei no 8.033, de 2 de dezembro de 1975. Disponível em: <http//www.pm.go.gov.br/index. php?link=37\&t=24\&id=73464>. Acesso em: 17 mar. 2017.

GRAMSCI, Antonio. O leitor de Gramsci: escritos escolhidos 1916-1935. Organização e Introdução de Carlos Nelson Coutinho. Rio de Janeiro: Civilização Brasileira, 2011. (Leitores).

HOBSBAWN, Eric. Era dos Extremos: o Breve século XX (1914-1991). São Paulo, Companhia das Letras, 2003. 
MACEDO, Jussara Marques de. LAMOSA, Rodrigo. A Regulação do Trabalho Docente no Contexto da Reforma Gerencial da Educação. Revista Contemporânea de Educação, Rio de Janeiro, v. 10, n. 20, p. 133-152, jul./ dez. 2015.

MESZÁROS, Istévan. A Crise estrutural do Capital. 1. Ed. São Paulo: Boitempo, 2009.

O POPULAR. Goiás terá mais dez colégios da Polícia Militar em 2018; saiba onde. 15 mar. 2017. Disponível em: $<$ https://www.opopular.com.br/editorias/cidade/goiás-terá-mais-dez-colégios-da-polícia-militar-em-2018-saiba-onde-1.1241190 >. Acesso em: 15 jul. 2017.

SOUZA, José dos Santos. A educação profissional no contexto da reengenharia institucional da política pública de trabalho, qualificação e geração de renda: novos e velhos mecanismos de manutenção da hegemonia burguesa no governo FHC. Trabalho Necessário, ano 11, n. 16, p. 1-36, jan./jun. 2013.

. O Sindicalismo Brasileiro e a Qualificação do Trabalhador. 2. ed. Bauru: Editora Práxis; Canal 6, 2015.

TIRADENTES, A. de F. dos S. Pedagogia do Mercado: Neoliberalismo, Trabalho e Educação no Século XXI. 1. ed. Rio de Janeiro: IbisLibris, 2012.

Recebido em: 30/09/2017 Aprovado em: 22/12/2017 Publicado em: 30/04/2018 